\title{
Janssen in China and insights in treating schizophrenia
}

\author{
John Cookson
}

\author{
COMMENTARY ON... COCHRANE CORNER ${ }^{\dagger}$
}

\begin{abstract}
SUMMARY
This Cochrane review supports existing recommendations for risperidone and advances understanding of the use of valproate in patients with schizophrenia who are agitated or aggressive.
\end{abstract}

\section{DECLARATION OF INTEREST}

J.C. conducted clinical trials of antipsychotics sponsored by Janssen Pharmaceuticals between 1978 and 1998 and met Dr Paul Janssen.

\section{Keywords}

Schizophrenia; anticonvulsants; antipsychotics; in-patient treatment; mood stabilisers.

The review in this month's Cochrane Corner (Ostinelli 2018) concerns the use of risperidone in situations that might be described as acute tranquillisation rather than rapid tranquillisation, covering the time period up to 8 weeks after presentation with agitation or aggression in psychosis.

\section{Risperidone}

Risperidone, like haloperidol, is a product of the creative genius of Paul Janssen (1926-2003), the Belgian physician and chemist and founder of the Janssen pharmaceutical company, now part of Johnson \& Johnson.

Haloperidol, a butyrophenone with antipsychotic properties, had been synthesised in 1958 as a variant of the pethidine molecule and became widely used in treating acute schizophrenia and mania (Chou 1996), including as parenteral injections for acutely disturbed people with psychosis ('rapid tranquillisation') and as the standard comparator treatment in trials of new drugs in schizophrenia.

The occurrence of neurological (Parkinsonian) side-effects with older ('neuroleptic') antipsychotics, including haloperidol, stimulated the development of alternative drugs, called 'atypical,' 'second generation' or 'new', to avoid these side-effects. Risperidone is a newer antipsychotic that was developed by Janssen Pharmaceuticals and marketed from 1993.

The newer antipsychotic drugs may be classified according to the breadth of their pharmacological activity. The term serotonin and dopamine receptor antagonist (SDRA) is used to describe several, including risperidone, which is structurally similar to haloperidol.

Risperidone is an antagonist of dopamine $\mathrm{D}_{2}$ and serotonin 5- $\mathrm{HT}_{2 \mathrm{~A}}$ receptors - as are many other new antipsychotics. It also blocks histamine $\mathrm{H}_{1}$, noradrenaline (NA) alpha-1 and alpha-2 but not acetylcholine (ACh) receptors.

Unfortunately, risperidone, unlike haloperidol, is not available as a short-acting injection, but as tablets, rapidly dissolving orodispersible tablets and oral solution. There is no evidence that the last two are absorbed more quickly than standard tablets but they provide greater assurance of ingestion. Oral risperidone is subject to disintegration, dissolution, absorption and hepatic first-pass metabolism and cannot act as quickly as intramuscular haloperidol.

\section{Risperidone in meta-analyses and network meta-analyses in mania and schizophrenia}

In the treatment of schizophrenia, risperidone has greater efficacy than haloperidol and fewer extrapyramidal side-effects (Leucht 2013). However, it is not known whether this superiority applies to rapid tranquillisation.

By contrast, for reducing the symptoms of mania, no antipsychotic has proved to have greater efficacy than haloperidol but risperidone has comparable efficacy and is better tolerated (Cipriani 2011).

\section{Haloperidol and risperidone in guidelines for rapid tranquillisation}

Haloperidol, oral or intramuscular, is recommended for use in rapid tranquillisation in many guidelines but a recent Cochrane review of the use of haloperidol for rapid tranquillisation (Ostinelli 2017) warns: 'Where additional drugs are available, sole use of haloperidol for extreme emergency could be
ROUND THE CORNER
John Cookson is a consultant in general adult psychiatry for the Royal London Hospital and East London NHS Foundation Trust. He trained in physiology and pharmacology at the University of Oxford and he has a career-long interest in psychopharmacology. His duties have included work in psychiatric intensive care units since 1988. He has coauthored two editions of Use of Drugs in Psychiatry, published by Gaskell.

Correspondence Dr John Cookson, Tower Hamlets Centre for Mental Health, Mile End Hospital,

Bancroft Road,

London E1 4DG, UK.

Email: john.cookson1@nhs.net

\section{Copyright and usage}

(c) The Royal College of Psychiatrists 2018

\section{${ }^{\dagger}$ See this issue.}


considered unethical'. An anticholinergic drug such as procyclidine or the sedative anticholinergic antihistamine promethazine should be combined with haloperidol. For oral use risperidone is widely seen as the modern equivalent of haloperidol with fewer extrapyramidal side-effects.

National Institute for Health and Care Excellence (NICE) guidelines on rapid tranquillisation do not mention specifically the use of risperidone. The 2005 guidelines (National Collaborating Centre for Nursing and Supportive Care 2005) recommended oral antipsychotics without specifying a particular drug. The updated edition of these guidelines (National Collaborating Centre for Mental Health 2015) does not include discussion of oral medication, having re-defined rapid tranquillisation as the use of intramuscular medication only (see Cookson 2018).

A consensus statement from the American Association for Emergency Psychiatry (AAEP) concludes: 'In the limited number of studies that have compared oral antipsychotics, the combination of oral risperidone + lorazepam is as efficacious as intramuscular haloperidol + lorazepam, and oral risperidone alone is as efficacious as intramuscular haloperidol alone' (Wilson 2012).

Joint guidelines from the British Association for Psychopharmacology (BAP) and the National Association of Psychiatric Intensive Care and Low Secure Units (NAPICU) (Patel 2018) on management of acute disturbance address oral medication, which they describe as 'pre-rapid tranquillisation' or 'as required' (pro re nata, PRN), given to avert violence while the agitated patient is still willing to accept oral medication. Risperidone is included as one of the options, along with haloperidol and other alternative agents.

The AAEP statement is justified by reference to studies by Currier et al (2004), Hsu et al (2010) and Lim et al (2010). The BAP NAPICU guidelines refer additionally to Lejeune et al (2004). A study by Potkin et al (2006), which was not reviewed by the AAEP or BAP NAPICU, also supports use of risperidone. As shown in Tables 1 and 2, four of these studies are randomised controlled trials (RCTs), covering response up to 24 hours (Currier 2004; Hsu 2010; Lim 2010) and over 2 weeks (Potkin 2006). Only Potkin et al (2006) was placebo-controlled. Lejeune et al (2004) is a patient-choice study, covering the early response up to 2 hours. Only one of these trials (Lim 2010) was included in Ostinelli et al's (2018) Cochrane review (Table 2). Table 1 summarises the other four, with the reasons they were not included. Overall, they point to oral risperidone (usually given in combination with lorazepam) being non-inferior to intramuscular haloperidol from 2 hours to 2 weeks,

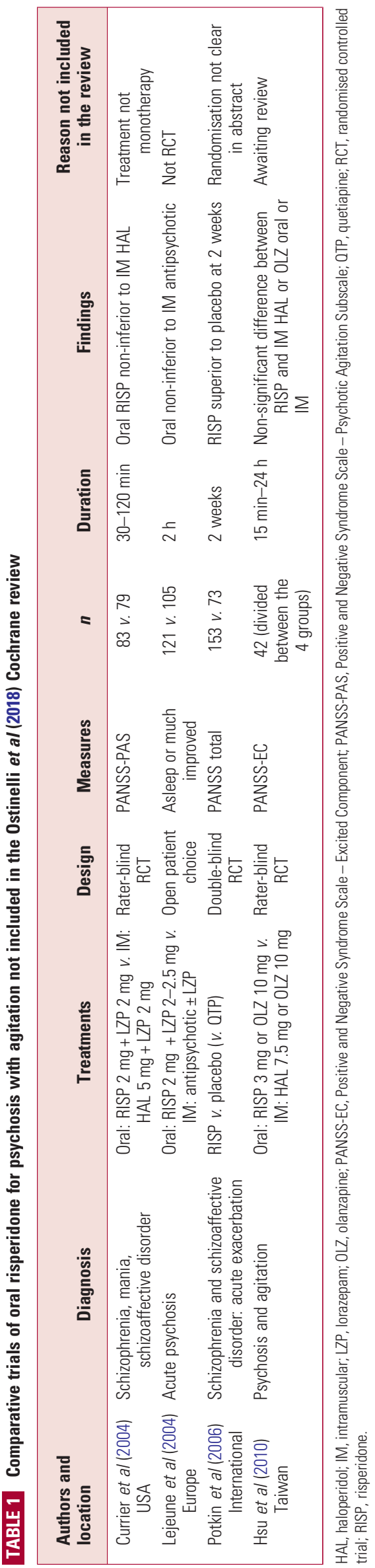


TABLE 2 Randomised controlled trials of risperidone for psychosis with agitation analysed in the Ostinelli et al (2018) Cochrane review

\begin{tabular}{|c|c|c|c|c|c|c|c|c|}
\hline $\begin{array}{l}\text { Authors and } \\
\text { location }\end{array}$ & Journal & $\begin{array}{l}\text { English } \\
\text { language }\end{array}$ & Diagnosis & Measures & Comparison: daily doses & $n$ & Duration & Findings \\
\hline $\begin{array}{l}\text { Dai \& Chen (2012) } \\
\text { China }\end{array}$ & $\begin{array}{l}\text { Medical Journal of Chinese } \\
\text { People's Health }\end{array}$ & Abstract & ICD-10 schizophrenia with aggression & PANSS; MOAS & OTP 100-750 mg v. RISP 1-6 mg & 20 v. 20 & $2-8$ weeks & MOAS: OTP superior from 2 weeks \\
\hline $\begin{array}{l}\text { Lim et al (2010) } \\
\text { South Korea }\end{array}$ & Neuropsychobiology & Full & Schizophrenia and mania: agitation & PANSS-EC; YMRS & RISP 2-6 mg v. IM HAL 5-15 mg & 62 v. 62 & $30 \min$ to $24 \mathrm{~h}$ & RISP non-inferior \\
\hline $\begin{array}{l}\text { Walther et al } \\
\quad \text { (2014) } \\
\text { Switzerland }\end{array}$ & $\begin{array}{l}\text { Journal of Clinical } \\
\text { Psychopharmacology }\end{array}$ & Full & $\begin{array}{l}\text { Severe agitation in schizophrenia, } \\
\text { schizophreniform or } \\
\text { schizoaffective disorder }\end{array}$ & PANSS-PAS & $\begin{array}{l}\text { RISP } 2-6 \mathrm{mg} \text { v. HAL } 15 \mathrm{mg} \\
\text { v. } 0 \mathrm{LZ} 20 \mathrm{mg}\end{array}$ & $\begin{array}{l}14 \text { RISP; } 14 \mathrm{HAL} ; \\
\quad 15 \mathrm{OLZ}\end{array}$ & $2-96 \mathrm{~h}$ & No significant differences over $2 \mathrm{~h}$ to 4 days \\
\hline $\begin{array}{l}\text { Wang \& Qiu } \\
\quad \text { (2012) } \\
\text { China }\end{array}$ & $\begin{array}{l}\text { Medical Journal of Chinese } \\
\text { Civil Administration }\end{array}$ & Abstract & CCMD schizophrenia with agitation & BPRS; CGI & $\begin{array}{l}\text { RISP } 4.1 \pm 0.4 \mathrm{mg} \text { (OF) + OXC } 1.20 \\
\quad \pm 0.42 \mathrm{~g} \text { (OF) v. RISP } 4.2 \pm \\
0.35 \mathrm{mg}\end{array}$ & 35 v. 33 & 1-4 weeks & Combination superior from 1 to 4 weeks \\
\hline $\begin{array}{l}\text { Wang \& Jiang } \\
\text { (2013) } \\
\text { China }\end{array}$ & $\begin{array}{l}\text { Chinese Journal of Clinical } \\
\text { Rational Drug Use }\end{array}$ & No & CCMD schizophrenia with aggression & PANSS MOAS & $\begin{array}{l}\text { VAL } 600-1200 \mathrm{mg}+\text { RISP v. RISP } \\
\quad 1-6 \mathrm{mg}\end{array}$ & 34 v. 34 & 2-6 weeks & Combination superior from week 2 \\
\hline $\begin{array}{l}\text { Yao \& Jiang } \\
(2010) \\
\text { China }\end{array}$ & Occupation and Health & Abstract & CCMD schizophrenia with aggression & PANSS & $\begin{array}{l}\text { Mg VAL } 500 \mathrm{mg}+\text { RISP } 1-6 \mathrm{mg} \\
\quad \text { v. RISP }\end{array}$ & 31 v. 31 & 2-8 weeks & Combination superior from 4 to 8 weeks \\
\hline $\begin{array}{l}\text { Zhou et al (2013) } \\
\text { China }\end{array}$ & $\begin{array}{l}\text { Journal of Clinical } \\
\qquad \text { Psychological Medicine }\end{array}$ & Abstract & CCMD schizophrenia with agitation & PANSS-EC; MOAS & $\begin{array}{l}\text { IV VAL } 400 \mathrm{mg} \text { twice daily + RISP } \\
4 \mathrm{mg} v \text {. RISP }\end{array}$ & 27 v. 27 & $6 \mathrm{~h}$ to 7 days & $\begin{array}{l}\text { MOAS: combination superior on days } 3,7 \text {; PANSS-EC: } \\
\text { combination superior from day } 5\end{array}$ \\
\hline $\begin{array}{l}\text { Jin (2013) } \\
\text { China }\end{array}$ & $\begin{array}{l}\text { Chinese Journal of Modern } \\
\text { Drug Application }\end{array}$ & No & Psychosis: aggressive & PANSS & $\begin{array}{l}\text { Mg VAL } 750-1000 \mathrm{mg}+\text { RISP } \\
\text { v. RISP (RISP doses not } \\
\text { stated) }\end{array}$ & 32 v. 31 & 2-4 weeks & $\begin{array}{l}\text { Combination superior at 2-4 weeks on PANSS total } \\
\text { score, Positive Symptoms and General } \\
\text { Psychopathology Subscales }\end{array}$ \\
\hline $\begin{array}{l}\text { Li et al (2013) } \\
\text { China }\end{array}$ & $\begin{array}{l}\text { Journal of Practical Medical } \\
\text { Techniques }\end{array}$ & No & ICD-10 schizophrenia: aggressive & PANSS; MOAS & $\begin{array}{l}\text { Mg VAL } 750-1000 \mathrm{mg}+\text { RISP } \\
\text { v. RISP } 1-6 \mathrm{mg}\end{array}$ & 30 v. 30 & 2-8 weeks & $\begin{array}{l}\text { Combination superior on PANSS total score and Positive } \\
\text { Symptoms Subscale and on MOAS from } 4 \text { weeks }\end{array}$ \\
\hline
\end{tabular}

BPRS, Brief Psychiatric Rating Scale; CCMD, Chinese Classification of Mental Disorders.; CGI, Clinical Global Impression; HAL, haloperidol; IM, intramuscular; IV, intravenous; Mg VAL, magnesium valproate; MOAS, Modified Overt Aggression Scale; OF, oral formulation; OLZ, olanzapine; OXC, oxcarbazepine; PANSS, Positive and Negative Syndrome Scale; PANSS-EC, Positive and Negative Syndrome Scale - Excited Component; PANSS-PAS: Positive and Negative Syndrome Scale - Psychotic Agitation Subscale; QTP, quetiapine; RISP, risperidone; VAL, valproate; YMRS, Young Mania Rating Scale. 
with some evidence of intramuscular haloperidol being faster.

\section{The Cochrane review}

\section{Literature search and analysis}

Ostinelli et al (2018) obtained articles referring to 70 studies - 57 were excluded with reasons, 4 were identified as awaiting assessment and 9 were included in the review.

The papers selected are listed in Table 2. Only one of these (Lim 2010) refers to the first day of treatment. Overall, $89 \%$ of participants had a diagnosis of schizophrenia, and 7\% bipolar I disorder with or without psychotic symptoms. Of the nine papers only two are published in English (one from Switzerland and one from South Korea). The others are published in journals that are difficult to access from the UK; four have English language abstracts and three are entirely in Mandarin Chinese. Cochrane had translations made. Ostinelli et al are critical of these papers for not containing sufficient details (such as procedures for randomisation, dosage and masking/blinding) and for incomplete outcome data and reporting bias. Only two gave outcome data earlier than 3 days. Most are brief reports lacking detail and accessible conclusions.

Potential debate about the quality of the Chinese trials could be resolved if they were published in fuller detail in journals with recognised peer-review/ refereeing standards and English translations.

Three trials compared risperidone with an active comparator - haloperidol (oral or intramuscular), quetiapine or olanzapine. However, five trials in China made a comparison between risperidone alone versus risperidone combined with valproate, while the other trial, also in China, examined the effect of combining oxcarbazepine with risperidone essentially, these six studies are tests of the efficacy of valproate or oxcarbazepine added to risperidone but not of risperidone itself.

The findings of the three active comparator studies (the first three trials listed in Table 2) add little about the efficacy of risperidone to what was known from the studies in Table 1. For patients with schizophrenia accompanied by agitation or aggression who are willing to take oral medication, risperidone was not inferior to intramuscular or oral haloperidol in reducing measures of agitation or aggression over periods from $30 \mathrm{~min}$ to $96 \mathrm{~h}$. It was inferior to quetiapine at 2 weeks in reducing aggression in one small study.

\section{The new evidence about valproate in treating schizophrenia}

In all five studies with valproate, as well as the study with oxcarbazepine, the combination proved more efficacious than risperidone alone in improving measures of agitation - presumed to be psychotically drive and other schizophrenia symptoms (Table 2). The time course of improvement was evident from 2 to 4 weeks with oral valproate, and within the first week with intravenous valproate or oral oxcarbazepine.

The Cochrane authors performed a meta-analysis on the valproate studies, concluding that for aggression, there was a clear difference with valproate from 5 days through to 6 weeks. There was also a clear difference in PANSS total scores at 2 and 4 weeks; the difference was seen by 6 weeks on the Positive Symptoms, Negative Symptoms and General Psychopathology Subscales.

\section{Does this change our understanding of management of aggression or agitation in psychosis?}

The findings on risperidone are consistent with current guidelines that regard it as a useful alternative to oral haloperidol. It would be of no use in patients requiring urgent tranquillisation, who would have to be given an injection. The findings on risperidone + valproate contrast with the prevailing opinion that there is a lack of RCT evidence that valproate may assist in the management of aggression when added to antipsychotics used for the treatment of schizophrenia (Lindenmayer 2000). A Cochrane review of valproate for schizophrenia concluded, cautiously, that despite evidence of greater improvement (especially in excitement and aggression) when valproate was added to antipsychotic medications, research was limited and firm conclusions could not be reached (Wang 2016).

\section{Conclusions}

Paul Janssen was described by Sir James Black as 'the most prolific drug inventor of all time' (Black 2005). He spoke Mandarin Chinese and set up a pharmaceutical manufacturing plant in Xi'an in Shaanxi province in 1985 (Andersen 2005).

It is impressive that Chinese psychiatrists have published these studies of risperidone, and they appear to have made a significant contribution to understanding the role of valproate in combination with risperidone in acutely disturbed psychotic patients. However, the research is difficult to access, and contains limited or no English translation. The papers are basically brief communications that lack important details. Only one of these studies (Lim 2010) was sponsored by Janssen.

This Cochrane review has not advanced knowledge to guide clinicians prescribing risperidone for acutely disturbed people with psychosis. It remains reasonable to prescribe the drug on the premise 
that, for patients with less urgent agitation who are aggressive or violent and are willing to take oral medication, oral risperidone is as efficacious as intramuscular haloperidol in reducing agitation in schizophrenia and mania over a period of 2 to $24 \mathrm{~h}$.

On the other hand, the review has contributed, perhaps unwittingly, to understanding the role of valproate in psychosis accompanied by aggression or agitation, showing its usefulness at least over 8 weeks. In a previous Cochrane review, its use as adjunctive treatment in the management of schizophrenia was concluded to have a limited evidence base (Wang 2016). However, four of the present studies were not included in that analysis because a Chinese translation was awaited. The benefit claimed here would make the management of aggressive behaviour easier over a period of days rather than hours. It is not clear whether initial loading doses of valproate would hasten the improvement.

Valproate is not recommended for managing aggression in schizophrenia in either NICE (National Collaborating Centre for Mental Health 2015) or BAP NAPICU (Patel 2018) guidelines. Any use of valproate in females should pay very careful attention to the possibility of pregnancy. All prescribers must be aware that it should not be prescribed to women of child-bearing age, because of the risk of harmful effects on the foetus (NICE 2016).

\section{Acknowledgements}

I am grateful to Dr Jonathan Pimm for assistance on this manuscript.

\section{References}

Andersen J (2005) How Paul Janssen's drugs saved the Chinese warriors. Pharmacologist, 57: 28-56.

Black SJ (2005) A personal perspective on Dr. Paul Janssen. Journal of Medicinal Chemistry, 48: 1687-8.

Chou JC, Zito JM, Vitrai J, et al (1996) Neuroleptics in acute mania: a pharmacoepidemiologic study. Annals of Pharmacotherapy, 30: 1396-8.

Cipriani A, Barbui C, Salanti G, et al (2011) Comparative efficacy and acceptability of antimanic drugs in acute mania: a multiple-treatments meta-analysis. Lancet, 378: 1306-15.

Cookson J (2018) Rapid tranquillisation: the science and advice. BJPsych Advances, 24: 346-58

Currier GW, Chou JCY, Feifel D, et al (2004) Acute treatment of psychotic agitation: a randomized comparison of oral treatment with risperidone and lorazepam versus intramuscular treatment with haloperidol and lorazepam. Journal of Clinical Psychiatry, 65: 386-94.

Dai L, Chen QL (2012) The comparative study of quetiapine versus risperidol [sic] for aggressive behaviour in people with schizophrenia. Medical Journal of Chinese People's Health, 17: 2061-4.

Hsu W-Y, Huang S-S, Lee B-S, et al (2010) Comparison of intramuscular olanzapine, orally disintegrating olanzapine tablets, oral risperidone solution, and intramuscular haloperidol in the management of acute agitation in an acute care psychiatric ward in Taiwan. Journal of Clinical Psychopharmacology, 30: 230-4.

Jin $\mathrm{G}$ (2013) Efficacy of magnesium valproate for impulsive aggressive behavior in schizophrenia. Chinese Journal of Modern Drug Application, 7(14): 160-1.
Lejeune J, Larmo I, Chrzanowski W, et al (2004) Oral risperidone plus oral lorazepam versus standard care with intramuscular conventional neuroleptics in the initial phase of treating individuals with acute psychosis. International Clinical Psychopharmacology, 19: 259-69.

Leucht S, Cipriani A, Spineli L, et al (2013) Comparative efficacy and tolerability of 15 antipsychotic drugs in schizophrenia: a multiple-treatments meta-analysis. Lancet, 382: 951-62.

Li C, Liu Y, Wang M (2013) Magnesium valproate sustained release tablets in combination with risperidone for impulsive aggressive behavior in people with schizophrenia. Journal of Practical Medical Techniques, 20: 69-71.

Lim HK, Kim JJ, Pae CU, et al (2010) Comparison of risperidone orodispersible tablet and intramuscular haloperidol in the treatment of acute psychotic agitation: a randomized open, prospective study. Neuropsychobiology, 62: 81-6.

Lindenmayer JP, Kotsaftis A (2000) Use of sodium valproate in violent and aggressive behaviors: a critical review. Journal of Clinical Psychiatry, 61: 123-8.

National Collaborating Centre for Mental Health (2015) Violence and Aggression: Short-Term Management in Mental Health, Health and Community Settings: Updated Edition (NICE Guideline NG10). British Psychological Society, Royal College of Psychiatrists.

National Collaborating Centre for Nursing and Supportive Care (2005) Violence: The Short-Term Management of Disturbed/Violent Behaviour in Psychiatric In-patient and Emergency Departments (NICE Clinical Guideline, No. 25). Royal College of Nursing.

National Institute for Health and Care Excellence (2016) Antenatal and Postnatal Mental Health (NICE Quality Standard OS115). NICE.

Ostinelli EG, Brooke-Powney MJ, Li X et al (2017) Haloperidol for psychosis-induced aggression or agitation (rapid tranquillisation). Cochrane Database of Systematic Reviews, 7: CD009377 (doi: 10.1002/14651858. CD009377. pub3).

Ostinelli EG, Hussein M, Ahmed U, et al (2018) Risperidone for psychosisinduced aggression or agitation (rapid tranquillisation). Cochrane Database of Systematic Reviews, 4: CD009412 (doi: 10.1002/14651858. CD009412.pub2).

Patel M, Sethi FN, Barnes TRE, et al (2018) Joint BAP NAPICU evidence-based consensus guidelines for the clinical management of acute disturbance: deescalation and rapid tranquillisation. Journal of Psychopharmacology, 32: $601-40$.

Potkin SG, Gharabawi GM, Greenspan AJ, et al (2006) A double blind comparison of risperidone, quetiapine and placebo in patients with schizophrenia experiencing an acute exacerbation requiring hospitalisation. Schizophrenia Research, 85: 254-65.

Walther S, Moggi F, Horn H, et al (2014) Rapid tranquilization of severely agitated patients with schizophrenia spectrum disorders: a naturalistic, rater-blinded, randomized, controlled study with oral haloperidol, risperidone, and olanzapine. Journal of Clinical Psychopharmacology, 34: 124-8.

Wang J, Oiu L (2012) A comparative study of risperidone merger oxcarbazepine in the treatment of schizophrenia agitation. Medical Journal of Chinese Civil Administration, 24: 2956-7.

Wang ML, Jiang TC (2013) Clinical observation of treatment with impulsive and aggressive behavior in patients with schizophrenia risperidone combined with valproate. Chinese Journal of Clinical Rational Drug Use, 6: 72-3.

Wang $Y$, Xia J, Helfer $H$, et al (2016) Valproate for schizophrenia. Cochrane Database of Systematic Reviews, 11: CD004028 (doi: 10.1002/14651858.CD004028.pub4).

Wilson MP, Pepper D, Currier GW, et al (2012) The psychopharmacology of agitation: consensus statement of the American Association for Emergency Psychiatry Project Beta Psychopharmacology Workgroup. Western Journal of Emergency Medicine, 13: 26-34.

Yao F, Jiang F (2010) Short-term efficacy of risperidone combined with magnesium valproate retard tablets on aggressive behavior in patients with schizophrenia. Occupation and Health, 26: 2713-14.

Zhou LC, Nong YX, Chen OM (2013) Risperidone monotherapy or in combination with valproate for agitation associated with schizophrenia. Journal of Clinical Psychological Medicine, 23: 261-2. 